\title{
Inequality, Unemployment and Growth: New Measures for Old Controversies ${ }^{1}$
}

\author{
James K. Galbraith \\ Galbraith@mail.utexas.edu \\ Lyndon B. Johnson School of Public Affairs \\ The University of Texas at Austin
}

Austin, Texas 78712

UTIP Working Paper No. 48

DOI: $10.1007 / s 10888-008-9083-2$

February 20, 2008

This paper is forthcoming in the Journal of Economic Inequality. The original publication is available at www.springerlink.com.

\begin{abstract}
:
This essays surveys some of the work of the University of Texas Inequality Project, a small research group that for the past decade has worked primarily to develop new measures of economic inequality, using a method based on the between-groups component of Theil's $\mathrm{T}$ statistic. In this way, inequality statistics can be computed from many diverse and mundane sources of information, including regional tax collections, employment and earnings, census of manufacturing, and harmonized international industrial data sets. The rich data environment so constructed permits new analyses of patterns of economic change, by region, by sector, and by country, and broadly supports the idea that the movement of inequality is closely related to macroeconomic events at the national and the global level.
\end{abstract}


"Kepler undertook to draw a curve through the places of Mars, and his greatest service to science was in impressing on men's minds that this was the thing to be done if they wished to improve astronomy; that they were not to content themselves with inquiring whether one system of epicycles was better than another, but that they were to sit down to the figures and find out what the curve, in truth was.” -- Charles Sanders Peirce (1877)

This essay surveys some of the work of the University of Texas Inequality Project, a small research group that for the past decade has worked primarily to develop new measures of economic inequality, using a method based on the between-groups component of Theil's T statistic. In this way, inequality statistics can be computed from many diverse and mundane sources of information, including regional tax collections, employment and earnings, census of manufacturing, and harmonized international industrial data sets.

These measures are broadly consistent with conventional, survey-based income inequality measures, or can be made so by statistical adjustment, after allowing for conceptual differences between pay and income. The advantage is that coverage in terms of countries and years is far greater, and the uniformity of method yields coefficients that are comparable both through time and across space. The UTIP method thus permits the formation of nearly balanced annual panel data sets with over three thousand country-year observations, covering over one hundred sixty countries over three or four decades. It therefore makes possible new investigations into the relationship between economic inequality and such macroeconomic phenomena as unemployment, national income, and economic growth. Measures of inequality may also be calculated both within and between regions in many countries. In some countries, inequality measures can be computed on a monthly basis, permitting the use of this statistic as a high-frequency macroeconomic indicator. 
This survey is organized as follows: Section 1 summarizes some of the problems associated with existing transnational inequality data sets. Section 2 presents the use of regional and sector data in the calculation of measures of inequality. Section 3 illustrates how Theil's T statistic can be grouped up or broken apart, so as to measure inequality at different levels of aggregation, for example using information on inequality within countries to derive a measure of the inequality between a group of countries considered jointly, in particular, inequality in Europe considered as a whole. Section 4 briefly describes UTIP's work on the relationship between global inequality and global macroeconomics, including the Kuznets relationship. Section 5 presents conclusions and some directions for further research.

\section{The Data Problem in Inequality Studies ${ }^{2}$}

If science consists in a search for patterns in data, then the study of economic inequality suffers from an original sin: the job of measurement was badly done. In most countries, measures of economic inequality were never incorporated routinely into national income accounts or labor statistics. As a result, data points across countries and through time are sparse, often conceptually inconsistent, and subject to the hazards of sampling error and differences in top-coding practice. Since one cannot take a retrospective survey, these defects cannot be repaired -- at least not by the same methods with which the original data were created. 
For students of the relationship between inequality and income, the quality of measures has been a problem ever since Kuznets (1955) formulated his famous curve. Kuznets based his postulate of an "inverted U" relation on the dynamics of industrialization and historical evidence for just a few countries, including the UK and the US. Many studies have since treated this relationship as a "stylized fact" (Ahluwalia 1976) or even as an "economic law" (Robinson 1976), but the longitudinal data required to test it rigorously on a broader basis have always been scarce. More recent theories attempt to relate an initial condition of inequality to later rates of growth, and whatever the form of that relationship, the test depends on having a broadly comprehensive data set; bias in the pattern of missing data points could skew the results either way.

In 1996, Deininger and Squire (hereafter DS) published a collection of many disparate surveys of income and expenditure inequality, and compiled those meeting certain criteria into a single "high-quality" panel, offering (in a widely-used version) 693 country/year observations since 1947. This monumental work was widely seen as a breakthrough, and in the past decade dozens of papers have used the DS compilation. The result has been less rather than more clarity about the Kuznets curve: in different papers, many different forms of the income-inequality relation have been specified, including both inverted and upright (Ram, 1997) "U" curves, and both upward (Forbes 2000) and downward-sloping (Perotti 1996) lines relating initial inequality and later growth. In other work, the use of the DS quintile shares to develop a measure of global between-households inequality (Sala-i-Martin, 2002), provoked a vivid protest from Milanovic (2002a, 2002b) on the ground of omitted observations and excessive interpolation. 
Efforts to expand the DS effort continue, notably at WIDER, the World Institute for Development Economics Research, at Helsinki. But (as those who work with them know well) the data remain problematic in many ways. Despite the growing number of observations, the coverage remains sparse and unbalanced, with very few "high quality" observations for many countries in the developing world. Moreover, as Atkinson and Brandolini (2001) point out, the DS inequality measures are based on various income definitions, reference units and processing procedures, which cannot be wholly reconciled to each other, even with "high-quality" filtering. ${ }^{3}$ In particular, differences in the type of survey conducted in different countries and regions, with income surveys favored in Latin America but expenditure surveys predominant in Asia, create an inconsistency that is not straightforward to resolve.

Within the OECD the DS data provide comparative measures that lack credibility on their face. For example, Spain appears as a low-inequality country, despite its relatively late emergence from fascism. On the other hand, the Scandinavian countries appear to be in the middle-range of OECD inequality, despite their small size, homogeneous populations, high union coverage, unified wage bargaining and long traditions of social democracy. Moreover, the trend of inequality is divergent across countries, suggesting an improbable “each country unto itself” pattern of change, in a world of common shocks and increasingly of shared policies. Figure 1, which ranks the OECD countries from left to right by their average DS score, and shows the first and last year of data for each country, illustrates these apparent anomalies. 
Figure 1. Measures of Inequality in the OECD from Deininger and Squire

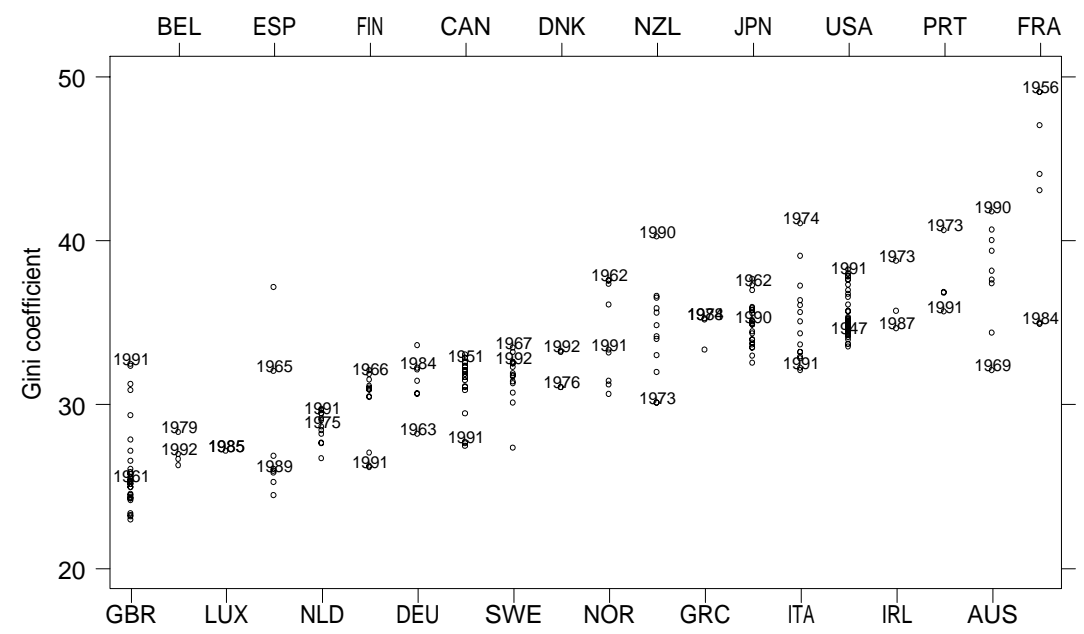

For those seeking an alternative to DS, the Luxembourg Income Studies (LIS) provide an attractive option, in the form of a harmonized transnational data set built from surveys. LIS also presents a considerably more plausible picture of the cross-sectional pattern of variations in income inequality within the OECD. But while the LIS coverage is gradually expanding (it will soon grow to 30 countries) it is even more sparse than DS, and not well-suited to panel or time-series analysis of inequality measures. LIS is therefore mainly a tool for the detailed analysis of differences in income, benefits and living standards. It is not designed for larger purposes, including a broader study of the Kuznets relation. ${ }^{4}$ Nor can either LIS or DS be used to probe the evolution of inequality at sub-national levels, for instance within and between states, provinces and regions of large countries such as the United States, Russia, China or Brazil. The question thus arises: can anything at all be done to create a stronger evidentiary foundation for analysis of economic inequality in comparative and historical perspective? 
2. Toward richer and denser measurement: The use of sector and regional data.

The work of UTIP is based on a simple insight: that the distribution of economic earnings is an approximate or statistical fractal, built up in any given national economy out of deeply interlaced institutional entities: firms, occupations, industries and geographic regions, and self-similar at different scales and from different points of view. That being so, consistent observation of part of the distribution is often - not always, but often - sufficient to reveal the main movements of the distribution as a whole.

Further, the movement of inequality in a given country, over time, is often determined by forces that work from the top down. These forces broadly differentiate the income paths of people working in different industries or in different parts of the country. Therefore, data sets which capture the average incomes of major groups of people, such as by industry or sector or region, may also contain a sufficiently large share of information on the evolution of inequality, so as to serve as good instruments for the movement of the distribution as a whole. These semiaggregated, categorical data sets, in other words, are an important data resource, not much used heretofore in work of this kind.

Over the past decade, UTIP researchers have explored the use of semi-aggregated economic datasets - that is, data organized and presented by economic sector or by geographic region - as a source of information on levels and changes in inequality. Published papers and books include Conceição and Galbraith 1999, Conceição, Galbraith and Bradford 2001, Galbraith and Berner 
2001, Galbraith and Kum 2003, 2005, Galbraith and Garcilazo 2004, 2005, Kim 2002, 2005, Galbraith, Krytynskaia and Wang 2004, Galbraith, RoyChowdhury and Shrivastava, 2004, Galbraith and Hale 2006, 2008, Galbraith, Pinto and Spagnolo 2007, Galbraith and Garza Cantu 1999, Galbraith and Ferguson 1999, Galbraith, Spagnolo and Munevar 2008, Galbraith 1998, 1999a, 1999b, 2002a, 2002b, 2007a, 2007b, 2007c.

Three general findings emerge from this work. First, economic data of a type suitable to these calculations are very common. Within the OECD coverage is universal, detailed, and available in consistent formats over long periods with short sampling intervals, annually back to the early 1960s, and monthly in many cases. Outside the OECD coverage is very broad; for example in Africa alone one can develop 703 cross-sectional data points through 1999. The corresponding number in DS is 63.

Second, sector and regional data yield richly detailed information concerning the precise pattern of winners and losers as inequality changes. One can see at a glance exactly which provinces and sometimes which cities gain, and at whose expense, and which precise sectors were advantaged and which were hurt in relative terms. ${ }^{5}$

Third, measures of pay or earnings inequality drawn from these non-survey-based sources are excellent instruments for the (unavailable) measures of income inequality that one might like to have. Where sample surveys exist, the pattern of matching is close, and where sample surveys do not exist, data of this type can be used to fill in gaps. For a sample of 485 observations matched by 
country and year, Galbraith and Kum (2005) show that inequality in manufacturing pay is a highly significant determinant of DS inequality, after controlling for survey type and for the share of manufacturing employment in population. The coefficients are very stable across alternative specifications, and the regression framework captures up to 60 percent of the variance in DS data.

The method of measurement is mathematically simple: it involves computing the between-groups component of Theil's T statistic, using the classification structure at hand as the grouping device. ${ }^{6}$ Theil (1972) showed that this measure is a consistent lower-bound estimate of total inequality ${ }^{7}$. Conceição, Galbraith and Bradford (2001) demonstrate that the T statistic is a statistical fractal: it is approximately self-similar at different scales. Since all members of the observed population are represented in the group structure (that is, one is working with a summary table from an underlying census), sampling issues do not arise ${ }^{8}$. Thus a coarse disaggregation of the data (say, a two-digit standard industrial classification ) typically yields the same general picture of movement through time as a fine disaggregation (say, a four-digit $\mathrm{SIC}^{9}$ ), but simply with less precision. It is true that coarse disaggregations capture less inequality than finer ones, and that up to very fine disaggregations, the method will almost always leave a larger share of total inequality within groups (and therefore unobserved) than between them. But once a reasonable degree of segmentation is achieved (usually a two-digit industrial classification and/or a high level geographic classification are adequate), the main patterns of change are discovered. Thereafter, refining the classification scheme does not greatly alter the pattern. The technique is similar to digital photography: everything is in the frame, and the relevant trade-off is between resolution and file size. 
Rich data sets are available for North America, Europe and many other countries, ${ }^{10}$ comprised of sectoral information nested within sub-national geographic regions, or of smaller geographic regions within larger ones. Thus, for the United States, it is possible to obtain detailed sectoral and also county decompositions for each state, so that the changing patterns of contribution to inequality by region and sector can be examined in fine detail. For Europe, it is possible to obtain measures of income by sector within provincial-level (NUTS-1) regions. This information can be displayed in a stacked bar graph, of which Figure 2 gives an example for income by county in the state of New York. ${ }^{11}$ The dominant role of wealthy Manhattan (New York County) in New York, and in increasing U.S. inequality in the 1980s, is plainly visible in the data.

Figure 2. Contribution of New York Counties to U.S. Inequality, 1969-2004

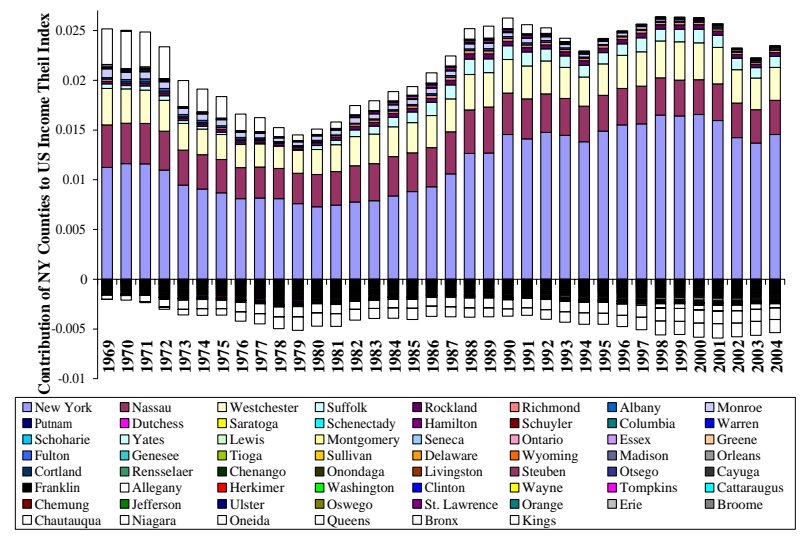

Compared to sample surveys, whose information about individuals is typically limited to a small number of personal characteristics, the information content of inequality measures done in this way is very high and the approach opens many avenues for detailed case studies of modern economies. But two points are especially important. 
First, since the collection of data by region and sector is usually a bureaucratic function conducted regularly and consistently by most governments, data of this type permit the creation of very long, dense, and complete time series of the movement of inequality. ${ }^{12}$ Second, where the underlying group structures are consistent across countries ${ }^{13}$, the between-groups component of Theil’s T statistic generates reliable between-countries measures of inequality, which correspond closely to the rank orderings obtained by benchmark studies such as the LIS. ${ }^{14}$

These properties taken together mean that it is possible to convert measures of (say) industrial wage inequality computed using the Theil statistic into measures of estimated household income inequality, and so to generate dense, consistent data sets of income inequality measures in Gini format. The UTIP Estimated Household Income Inequality (EHII) data set has over 3,200 observations for the world economy, or roughly four times the coverage of DS, and all estimated on a single conceptual basis. ${ }^{15}$

Figure 3 presents EHII measures of gross household income inequality for the OECD countries, again ranked from left to right by average value, and again with first and last years indicated. Note that now the Scandinavian countries are low, while Spain, Portugal, Greece and the United States are high. Note also that the prevalent trend is toward increasing inequality in most if not all of the countries, Denmark being a lonely exception. A similar trend toward increasing inequality will be found in the EHII data for non-OECD countries, as we shall see. 
Figure 3. Income Inequality in the OECD: UTIP-EHII measures

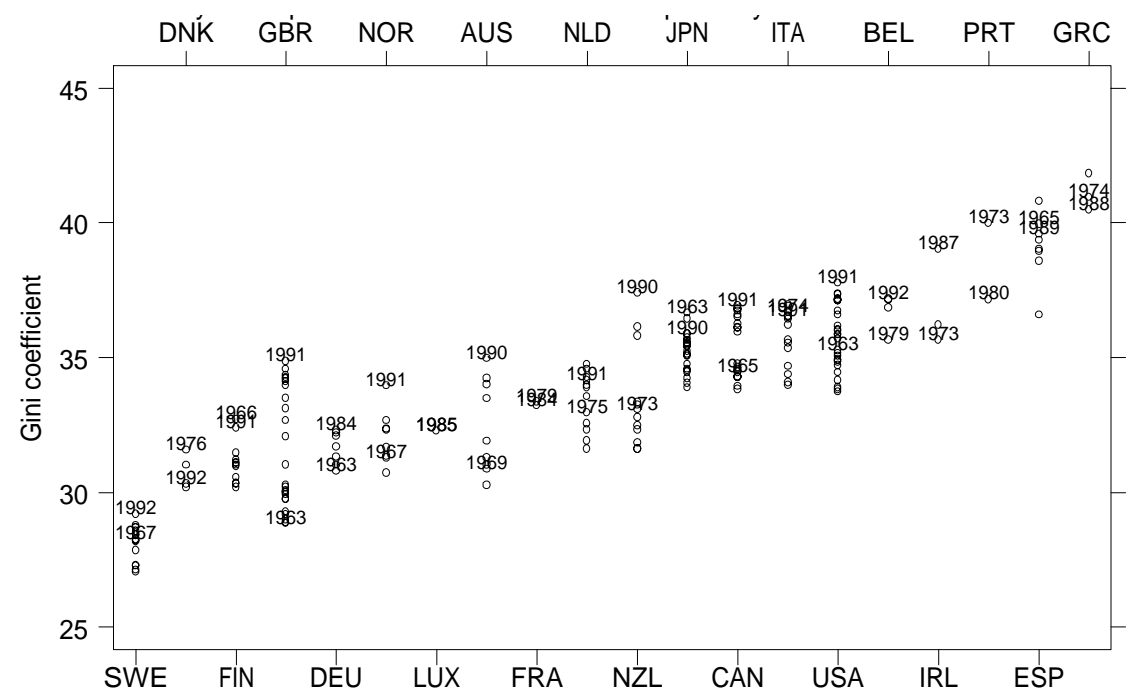

How reliable is this approach overall? We take the view that the close correspondence to existing measures of income inequality (once proper controls have been introduced), together with the depth of coverage and (in many cases) multiple data sets from which highly similar measures can be derived, all suggest that the EHII estimates are broadly reliable. But there are pitfalls and reservations, of which three encountered at various moments are especially worth noting.

First, where a country has a strong and volatile component of income driven by the capital markets, measures of the inequality of pay will not be good proxies for measures of the inequality of income. This is the case of the United States, where in the late 1990s income inequality rose while pay inequality fell. Pay inequality is an interesting variable in its own right: it is more closely related to trade, to technology, and to the inequality of expenditures than is income inequality. But the two concepts need not follow the same track. 
Second, under certain conditions, the between-groups method will give an inaccurate measure of the trend of pay inequality. This happens because censuses of business are inevitably partial: they ignore the grey economy, and censuses of manufacturing ignore the services sector. When the composition of employment changes abruptly, inequality measured within manufacturing can be a misleading indicator for pay inequality as a whole. In Britain in the early 1980s, for example, deindustrialization reduced low-wage employment in manufacturing and reduced inequality within the sector; but since most of those displaced experienced income declines, overall inequality in the UK economy rose. This is an unusual case but by no means a unique one.

Third, in parts of the world where the industrial sector is very small relative to the overall economy and where income inequality surveys are scarce, our experience is that all measures need to be treated with caution. In sub-Saharan Africa, very few countries have more than a bare handful of income surveys to work with, and these tend to show extreme inequality measures. The EHII method produces numerous data points, apparently consistent with each other, but with gini values that are generally much smaller than those arrived at in the surveys. There are three possible interpretations: (a) that sub-Saharan Africa has unique characteristics not seen elsewhere in the developing world, or (b) that the EHII method does not work well when manufacturing forms such a small fraction of total employment, or (c) that the available surveys were conducted on definitions and with methods different from those conducted elsewhere in the world. There is no way that we know of to decide between these hypotheses. We therefore simply note them, and pass on. 
3. Grouping up, from national to continental measures, and grouping down, from national to regional measures.

For valid economic inference, it is necessary that inequality be measured at the appropriate geographic and economic scale. However, researchers using survey data are limited by the (usually national) scope of the available surveys, and while the national scale is sometimes the appropriate one, this is clearly not always so. Combining surveys is difficult. One significant effort to combine national surveys into a single global data set of income between persons (Milanovic 2002b, 2007), was able to produce results for only three years $(1988,1993,1998)$. The effort was aimed at a substantially academic question, namely the trend of inequality among the human population as a whole. However, many practical questions depend on aggregating or disaggregating the observational unit to the correct level.

This section will discuss the uses of sector and regional data for the purpose of assessing inequality at other-than-national levels. Measures of this type can be computed readily, taking advantage of the aggregation/disaggregation properties of the Theil statistic. Thus it is possible to measure inequality (say, between regions) across the whole of continental Europe (say for the purpose of US-Europe comparisons), or equally to measure inequality (between sectors) at the level of European regions or American states. This is useful for analysis of labor markets or for voting analysis, among other questions.

The most urgent need for such data is apparent in modern Europe. Europe has become a single, 
complete, unified economy. It has no internal borders, no trade barriers, perfect capital mobility, and no formal barriers to migration. It has a common currency, for the most part. In taking this step, Europe abolished international-but-intra-European exchange rate fluctuation and also the intra-European current account. France's trade balance with Germany is today no more meaningful than that of Texas with New York.

Yet, if you wanted to know, say, the degree of inequality or the poverty rate in "Europe", where would you turn? Ideas are stuck where statistics are: at the national level. And so long as statistics drawn at the continental level are lacking, one cannot correctly model poverty, inequality, labor markets, or the effects of macroeconomic policy in “Europe.” For instance, under a system of unified European data, there would be virtually no poor in Germany and only a handful of "middle class" people in Poland or the Baltic states. ${ }^{16}$

Frequent comparison is also made between the inequality of pay in the United States and in Europe, for the purpose of explaining the chronically higher rate of European unemployment. Such comparisons (as in Figures 1 and 3), generally show the United States to be more unequal than most (though not all) countries of Europe. This finding tends to buttress the conventional conclusion, that the U.S. enjoys fuller employment because its labor markets are more "flexible," meaning they are more willing to reward high skills and to price low skills at rates that justify the employment of low-skilled labor.

Using the Theil method to assess the inequality of Europe as a whole overturns this argument. For 
while inequalities within many European countries are fairly low, those between European countries are quite large. Adding in the between-countries component of inequality, one finds that inequality in pay, in Europe, is substantially higher than in the U.S. This finding was first reported by Conceição, Ferreira and Galbraith (1999), who used the OECD Structural Analysis dataset to show that pay inequality measured across sectors in European manufacturing, taken as a whole, exceeded that in the US by around 30 percent. Galbraith (2007b) directly compares income inequality between the (subnational) regions of Europe with similar measures taken across the American states, both computed as between-regions Gini coefficients. These inequality measures for the EU-15 were 40 percent higher than in the U.S.; for the EU-25 inter-regional inequality proved to be more than twice that in the United States. ${ }^{17}$

These calculations suggest a different conclusion from the inter-continental comparison of inequalities: that the United States is more unequal at close range, while Europe is much more unequal over long distances. Unfortunately for the Europeans, inequalities at long distance are more significant for the determination of chronic unemployment, since they motivate displacement, migration, and the undermining of previously coherent national labor standards. Thus as Europe has become more integrated, both the relevant measure of inequality and the equilibrium rate of unemployment have gone up.

Equally useful, the ubiquity of region and sector data permits analyses of the relationship between inequality and other variables to be pursued at the sub-national level. In Europe, for example, there is a large variation in unemployment rates between the different regions within countries; 
this variation is sometimes larger than the variation of unemployment rates between countries. Yet, the standard analysis of European unemployment in terms of differing national labor market institutions can take no account of the variations arising within countries. Regional measures of inequality (a proxy for "labor market flexibility”) are well-adapted to this analysis. Garcilazo (2007) and Galbraith and Garcilazo (2004) present models based on regional data in Europe, including inequality measures. These models show that inequality is a significant determinant of unemployment at the regional level, in precisely the opposite sense suggested by the conventional theory: more inequality is associated with more, not less, unemployment.

A small amount of theoretical reflection can show that this result should not have been unexpected. Standard models of equilibrium unemployment under conditions of inequality, such as Harris and Todaro (1970) predict that high levels of inequality generate incentives to migrate and to search for employment, hence higher unemployment on a sustained basis. This pattern is clearly observed in European data. Further, the Swedish economists Meidner and Rehn (1951) postulated that wage compression would generate more rapid productivity growth, higher average incomes, and a greater capacity to absorb, retrain, and reemploy those displaced by technical change. The effects of this pattern too can be observed in modern Europe, where the Scandinavian countries have set the pace over the decades by running high employment, open economies with strongly compressed wage structures. The problem with the conventional view, emphasizing "labor market flexibility” as a cure for unemployment, is two-fold: it overlooks both migration incentives and endogenous productivity growth. It is therefore not surprising that the data do not fit. 
Regional inequality data are useful also for political analysis. The American states are political entities, an important fact given the state basis of the Electoral College. Panel measures of inequality within American states have been developed by Galbraith and Hale (2008) on principles similar to EHII; these can be correlated to measures of voting turnout and voter preference. Galbraith and Hale find that inequality suppresses turnout. They also identify a measure of geo-economic polarization ${ }^{18}$ within states which is highly correlated with recent presidential election outcomes. States which are highly polarized along spatial lines (generally, with a strong urban/suburban-rural divide) tend to vote Democratic; those that are predominantly rural or suburban tend to vote Republican. Intriguingly, as states have changed along this dimension (California and Connecticut are longstanding examples; Colorado and Virginia more recent ones) they have also evolved politically in the direction indicated by the model - that is, greater geo-spatial polarization inclines a state toward the Democratic Party.

Finally, measures of inequality at the subnational level can be used to explain the regional and sectoral basis of movements in the overall income distribution, as captured by sample surveys. For instance, standard Census measures of income inequality in the United States show a peak in 2000, followed by a decline. Galbraith and Hale (2006) show that this measure is closely tracked by a measure of income inequality calculated from tax data tabulated at the county level. Thus variations observed between American counties are, for this period at least, a good instrument for variations occurring in the whole population.

Further, a measure based on counties can offer quite precise insight into the sectoral causes of 
rising income inequality. Galbraith and Hale (2006) found that the Theil measure of inequality across counties over 33 years (1971-2004) is highly correlated to the (log) of the NASDAQ stock price index, with the principal contributions to rising inequality coming from the counties of Silicon Valley and similar technology centers. They find that if the income growth of just five counties ${ }^{19}$ were removed from the data, almost the entire increase in between-county income inequality in the late 1990s United States would have disappeared. The decline in inequality that followed is entirely explained by the stock market crash, which was centered on the technology stocks. Figure 4 presents the two series.

Figure 4. Inequality Between Counties in the US and the (log) NASDAQ stock index, 1971-2004.

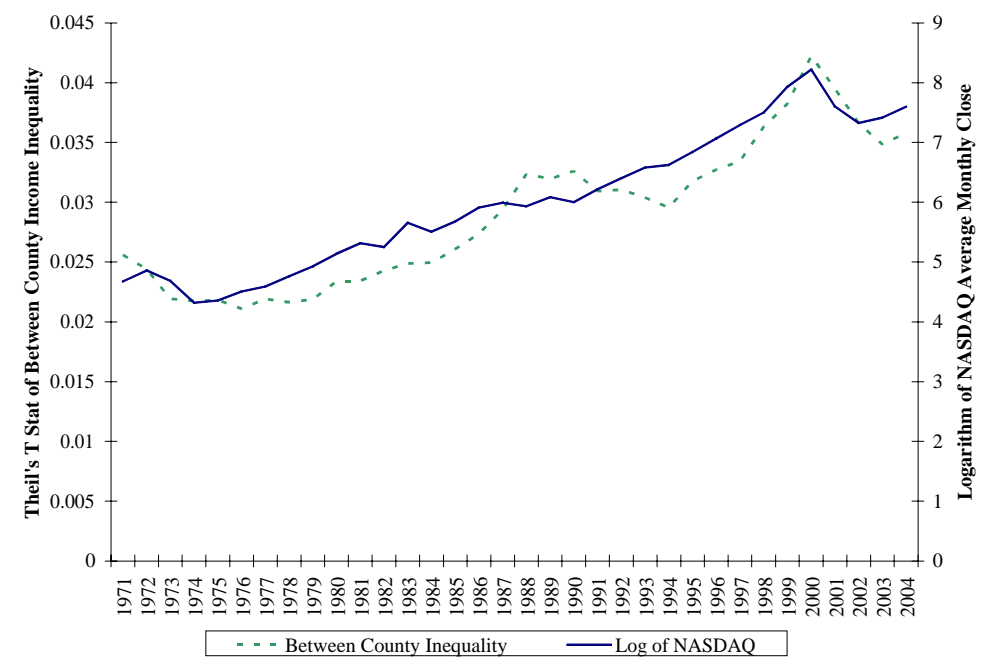

Overall, this research underlines the importance of distinguishing carefully between sources of income in the United States. As the "econophysics” literature has recognized, the distribution of what is called income is an amalgam of two very different things: the distribution of earnings or 
pay, which tends to follow a (statistically-most-probable) Boltzmann distribution, and the distribution of property income ${ }^{20}$, which dominates the top of the scale and tends to follow a power law (Chatterjee, Yarlagadda, and Chakrabarti, 2005). Since the ownership of stocks is skewed to the top of the distribution, the parameters of the power law vary with valuations in the stock market. This, along with the comparative stability of pay-based incomes, accounts for the high degree of correlation between stock prices and the income distribution. It also demonstrates that the distribution of taxable income is a very poor proxy for inequality in labor income. Finally, it demonstrates that the issue of rising income inequality in the United States is not, by and large, a phenomenon that runs from the top to the bottom of the structure. It is, rather, a phenomenon that reflects, in the main, an extreme increase in incomes of a tiny group at the very top of the structure.

The distribution of earnings reflects an institutional structure of wage rates which is governed by structured relativities within organizations and is generally very stable (Galbraith 1998, Kitov 2005, 2007). Despite the focus of economic theory on the effects of technology, trade, immigration and other forces on hourly wage rates, the latter are not observed directly; almost all of the empirical work on changing wage distributions relies on measures of weekly or monthly earnings. The variation in earnings is largely a matter of fluctuations in hours worked (which may trigger overtime payments, affecting the average hourly wage but not the notional wage rate). Inequality in earnings is therefore closely related to open unemployment, as Figure 5 illustrates using monthly data for American manufacturing from 1953 to 2005 (with shaded periods indicating recessions). Significant effects of labor-force participation and of the exchange rate on this measure have also been found (Giovannoni 2007, Galbraith 1998), and Galbraith, Giovannoni 
and Russo (2007) show that it is Granger-caused by the movement of the term structure, a measure of the stance of monetary policy. This finding has interest in part because Federal Reserve officials have been at pains, on regular occasion, to deny the proposition that monetary policy can affect inequality. But the evidence for pay inequality strongly indicates that it does. And indeed, to the considerable extent that monetary policy influences the stock market, one can also argue that the pattern of overall income inequality is also substantially affected by the stance of monetary policy.

Figure 5. Pay Inequality in Manufacturing and Unemployment in the US, 1953 - 2005, Monthly Data. (recessions marked in grey.)

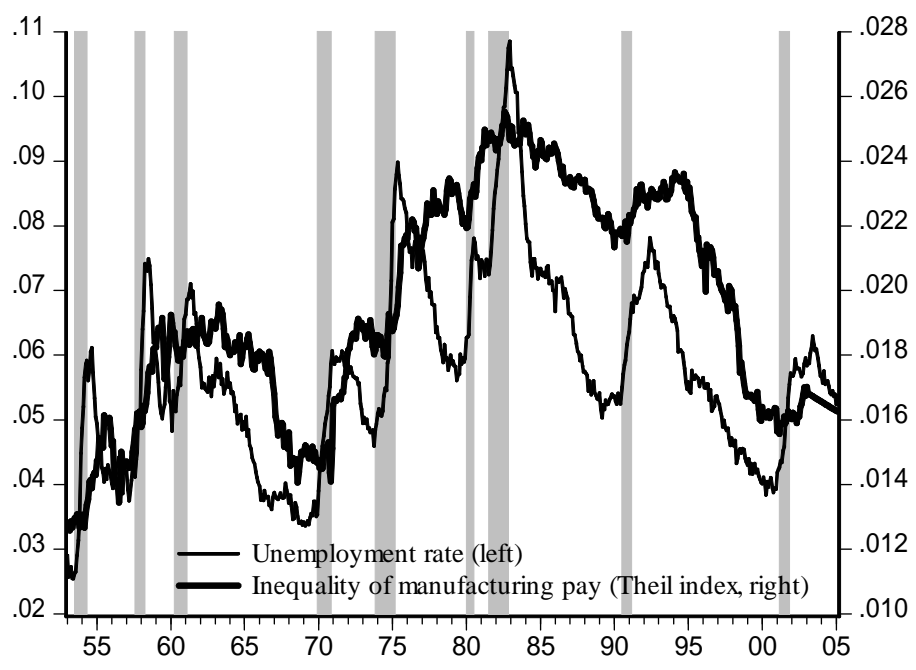

Similar results hold for Europe, where inequality as a whole declined with declining unemployment from 1995 to 2000 (Galbraith and Garcilazo, 2005). Moreover, an analysis of unemployment by regions in Europe reveals a common time pattern, which strongly associates the rise in unemployment across the continent with the implementation of the Maastricht Treaty in 1993 (Galbraith and Garcilazo 2004). This pattern provides support to those who argue that 
European unemployment has an important macroeconomic component, determined by the policy stance of European authorities taken together and as a whole.

But this leaves open the question: what exactly explains the relationship between equality and employment -- in Europe and elsewhere? The next section takes up some of the theoretical questions raised by the relationships that are evident in the data.

\section{Global Inequality and Global Macroeconomics}

Galbraith 2007c surveys the contribution of the UTIP team to the development of global inequality data sets. Key contributions in this area were Galbraith and Kum 2003, which presents a uniform comparative data set of pay inequality measures from the UNIDO Industrial Statistics data base (UTIP-UNIDO), and Galbraith and Kum 2005, which converts those Theil measures into consistent estimates of country-level household income inequality (EHII), with over 3200 country-year observations in each case.

The UTIP-UNIDO global data effort can be used to demonstrate that, in the end, Kuznets was broadly right: the correct specification of the relationship between pay inequality and development is of a curve relating levels of inequality to levels of income. Further, the relationship is broadly downward sloping in most countries: strong growth reduces inequality, most of the time. However there are exceptions at both tails of the distribution. China is a low-income country still in the canonical transition of agriculture to industry; hence inequality rises with more rapid growth there. 
The United States and a few other advanced countries are on upward-sloping Kuznets surfaces for a different reason: they supply capital goods to world markets and so the highest incomes vary positively with the business cycle (Galbraith 1998, Conceição and Galbraith 2002). The "augmented Kuznets curve" that takes all of this into account appears to have the form of a sideways inverted S. Figure Six provides a stylized illustration.

Figure 6. Stylized augmented Kuznets curve, with selected countries in illustrative positions.

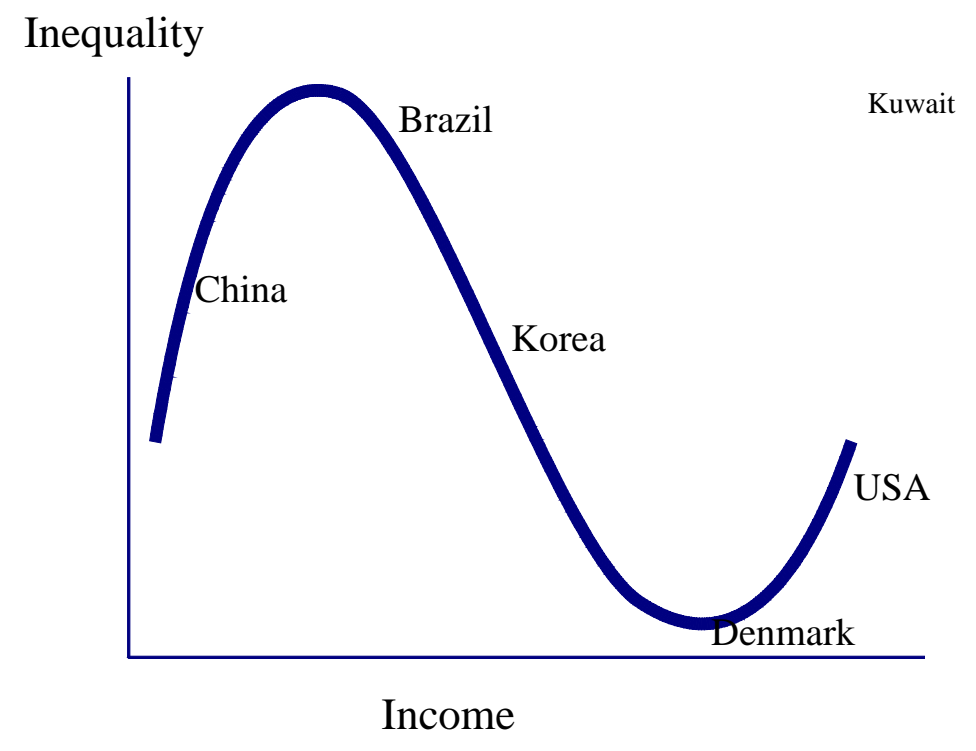

The rich panel structures of the UTIP-UNIDO and EHII data sets permit a search for comprehensive global patterns in the movement of inequality; Galbraith and Kum $(2003,2005)$ demonstrate that these exist. There are two turning points: from stability to declining inequality around 1973, and from declining to sharply rising inequality around 1982, with the latter pattern persisting until the end of the millennium. The timing and the world-spanning character of these 
shifts strongly point to the contemporaneous changes in the global financial regime as bearing responsibility: specifically at the destruction of Bretton Woods in unleashing the commodities/debt boom of the 1970s, and at the rise of global monetarism in 1979-81 in unleashing the debt crisis and the new era of high real interest rates, which reverberated around the world until 2001. Thus the data, quite free of any a priori or theoretical considerations, point toward the existence of a unified global economy and of powerful macroeconomic forces affecting many countries simultaneously. Such matters as oil prices and global interest rates would be expected to have the requisite global reach, and the pattern of effect - with rising oil prices corresponding to reduced inequality in producer countries and to increased inequality among consumers, for instance - suggests that these are, indeed, among the principal forces at work.

So pronounced are these global patterns (isolated as the time fixed effects in a two-way fixed-effects panel regression) that without them, inequality would have declined in the world economy, rather than rising in almost every country and region. Figure Seven illustrates, using UTIP-UNIDO data. On the left, we see the actual pattern of pay inequality across some 200 countries, divided into to OECD and non-OECD members, with error bands indicating the standard deviation of each group, each year. On the right, we see the same data with the estimated global component removed: what would have happened to inequality had the world economic climate not placed such stress on individual countries. 
Figure 7. Actual and stimulated pay inequality: A comparison with and without the global component of rising inequality after 1981

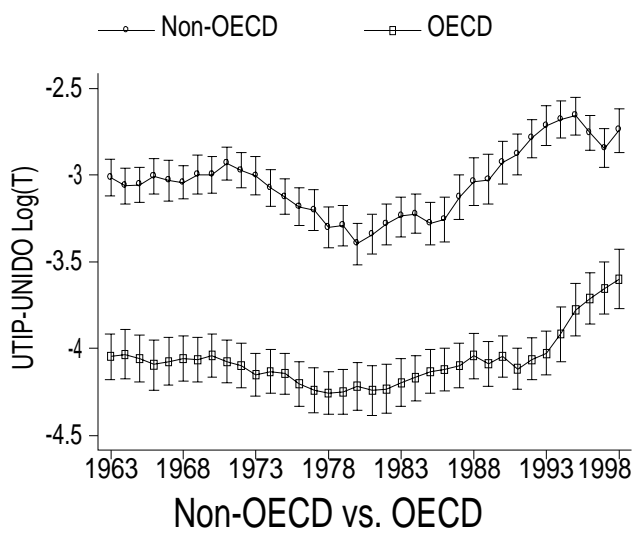

(Actual Values)

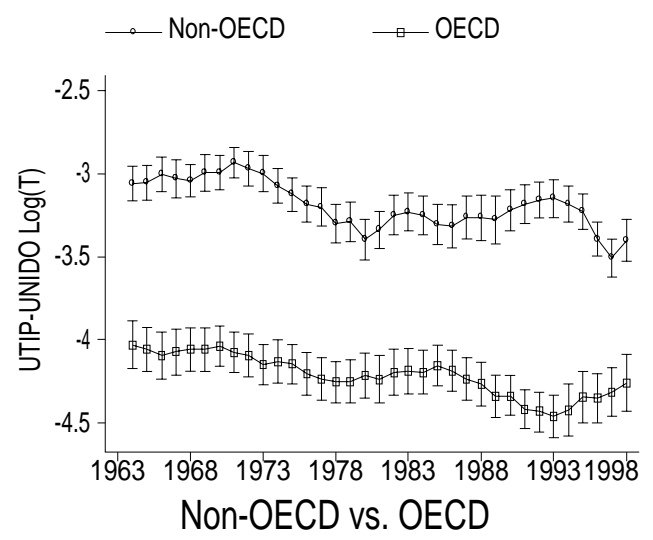

(After Global Effect Removed)

Finally, UTIP researchers have mined purely national data sources to develop measures of inequality by sector within provinces or regions for the following countries so far: Argentina, Brazil, Chile, China, Costa Rica, Cuba, Colombia, India, Mexico, Russia, the United States, Taiwan, and all of Europe at the regional level. These data sets permit a careful evaluation of the evolution of urban-rural and other differentials, including the changing fortunes of economically powerful sectors such as banking, utilities, energy and transportation. UTIP work documents the decline in inequality in recent years in the southern cone of Latin America, following that region's retreat from neoliberal orthodoxy in the wake of the financial crises of the late 1990s and early 2000s. This is mainly due to a shrinkage in the formerly outsized importance of the financial sector, a corresponding shrinkage in the relative advantages held by the main financial centers, and a modest recovery of public sector employment. 


\section{Conclusions.}

The UTIP project has shown that industrial, sectoral and regional data can be deployed effectively to fill gaps and repair errors and inconsistencies in standard measures of economic inequality. The resulting data sets permit annual time-series and balanced panel regression analyses of inequality, practically for the first time, especially outside the OECD. Use of the Theil statistic also permits calculations of inequality measures at other-than-national scales, permitting for the first time that the choice of scale -- regional, national, continental or even global-- can be made endogenous to the research question.

These calculations have a disconcerting effect on conventional views of inequality. We have seen, among other things, that the movement of overall income inequality in the United States over time is largely governed by the stock market, an artifact of financial boom and bust. Meanwhile pay inequality in both the United States and Europe largely rises and falls with unemployment over time, although other factors including exchange rate movements and political regime changes play a role. Within Europe, countries with less pay inequality systematically enjoy less unemployment, other things equal. This result contradicts the "standard model” that places blame for chronic unemployment on labor market rigidity, though it is consistent with well-established models of search and migration and of induced productivity change. Further, an evaluation of inequality at the continental level demonstrates that pay inequality in the United States is less, not greater than in Europe. Again this tends to refute the view that the superior employment performance of the United States is due to high inequality in pay structures, and calls attention instead to the neglected 
international dimension of European inequality - a dimension of increasing relevance as the continental economy becomes more integrated.

Looking at the broader world economy, we find that data support the basic intuition of Kuznets: the level of inequality is associated with the level of income. However, the form of this relationship appears more complex than the conventional inverted U-curve that is widely associated with Kuznets in the literature. The incidence of poor countries on an upward-sloping curve appears low; China and India are perhaps the major examples in the world today. Most countries tend to experience falling inequality as they grow and develop. However, there is evidence that for some of the richest countries, notably capital goods exporters and the small oil producers, rising incomes are associated with rising inequality once again.

Finally, there is a strong global pattern to the movement of inequality, with a rise, quite independent of changes in national income, beginning in the early 1980s. This pattern strongly suggests that the proper conceptual domain for the study of global inequality is macroeconomic, and that macroeconomic forces common to the entire global economy can be identified in the data.

The personal or household distribution of income has traditionally been considered as a problem largely in applied microeconomics, specifically labor economics. But the UTIP data environment points to a different conclusiont. It suggests, instead, that macroeconomics can provide a theoretical framework capable of explaining the relationship between inequality, unemployment and growth in a coherent way. 
Thus this framework has three major theoretical underpinnings: a theory of rational search in an unequal world, based on Harris and Todaro; a theory of induced technological progress, based on Rehn and Meidner, a theory of intersectoral transitions at the root of changes in inequality, based on Kuznets. Behind these lie, of course, the theory of aggregate effective demand, based on Keynes. Taken together, the framework and the evidence support a general conclusion that equality, employment and productive efficiency are broadly complements, not substitutes, at least within the general ranges experienced among OECD countries at the present time.

Much additional research remains to be done, particularly insofar as the task of compiling available data from national sources is far from complete. New work on services and the grey economy remains urgently needed. No doubt the broad picture sketched here can be filled out in many details as that work advances; it may yet be contradicted in some respects. Perhaps most important, as with any new data source, the UTIP work presents opportunities to researchers to study many different phenomena, from health to crime to war, in relationship to measures of inequality that are more precise, significantly more detailed, and in our view more reliable, than have been available before. 


\section{References}

Ahluwalia, M.S. (1976), "Inequality, Poverty and Development", Journal of Development Economics 3, 307-342.

Atkinson, A. and A. Brandolini (2001), "Promise and Pitfalls in the Use of Secondary Data-Sets: Income Inequality in OECD Countries as a Case Study", Journal of Economic Literature 34, 771-799.

Barro, R.J. (2000). "Inequality and Growth in a Panel of Countries", Journal of Economic Growth 5, 5-32.

Biancotti, Claudia, (2005). “A polarization of inequality? The distribution of national Gini coefficients 1970-1996?" Journal of Economic Inequality, v. 4, 1, pp. 1-32, TD No. 487.

Calmon, Paulo Du Pin, Pedro Conceição, James K. Galbraith, Vidal Garza-Cantú and Abel Hibert, (2000). “The Evolution of Industrial Wage Inequality in Mexico and Brazil,” Review of Development Economics, 4(2), 194-203, June.

Chatterjee, A., S. Yarlagadda, and B. K. Chakrabarti, (2005). Econophysics of Wealth Distributions, Milan: Springer-Verlag Italia. 
Conceição, Pedro, James K. Galbraith, and Peter Bradford, (2001), “The Theil Index in Sequences of Nested and Hierarchical Grouping Structures: Implications for the Measurement of Inequality Through Time, Galbraith, James K., Data Aggregated at Different Levels of Industrial Classification,” Eastern Economic Journal, 27(4), Fall, 491-514.

Conceição, Pedro, James K. Galbraith, and Pedro Ferreira, ( 1999). “Inequality and Unemployment in Europe: The American Cure,” New Left Review, No. 237, September-October, 28-51.

Conceição, Pedro and James K. Galbraith (2002), “Technological intensity and inter-sectoral dynamics of inequality: evidence from the OECD, 1970-1990,” International Journal of Technology Policy and Management, Vol. 2, No. 3, 315-337.

Conceição, Pedro and James K. Galbraith (2000), “Constructing Long and Dense Time Series of Inequality Using the Theil Statistic,” Eastern Economic Journal, 26(1), 61-74, June.

Deininger, K and L. Squire (1996). "A New Data Set Measuring Income Ine-quality", World Bank Economic Review 10, 565-591, Available at http://www.worldbank.org/research/growth/dddeisqu.htm.

Dollar, David and Art Kraay (2001). Growth Is Good for the Poor, World Bank Development Research Group, Manuscript. 
Forbes, K. (2000). "A Reassessment of the Relationship Between Inequality and Growth", American Economic Review 90, 869-887.

Galbraith, James K. and Maureen Berner, eds., (2001). Inequality and Industrial Change: A Global View, New York: Cambridge University Press.

Galbraith, James K., (1998). Created Unequal: The Crisis in American Pay, New York: The Free Press. A Twentieth Century Fund Book.

Galbraith, James K., (2007a) What is the American Model Really About? Soft Budgets and the Keynesian Revolution,” Industrial and Corporate Change 2007 16(1):1-18; doi:10.1093.

Galbraith, James K., (2007b). “Maastricht 2042 and the Fate of Europe: Toward Convergence and Full Employment.” Levy Economics Institute Public Policy Brief, No. 87, November 2006. Published separately by the Friedrich Ebert Stiftung, International Policy Analysis Unit, March.

Galbraith, James K., (2007c), “Global Macroeconomics and Global Inequality” in David Held and Ayse Kaya, eds., Global Inequality, Ralph Miliband Lecture Series on Inequalities at the London School of Economics, Cambridge: Polity Press, 2007, 148-175. Republished in Journal of Policy Modeling 29 (2007) 587-607.

“Galbraith, James K. (2002a), A Perfect Crime: Inequality in the Age of Globalization.” Daedalus, 
Winter, 11-25.

Galbraith, James K. (2002b), “The Importance of Being Sufficiently Equal,” Social Policy and Philosophy, Volume 19, Number 1, January-February.

“Galbraith, James K., (1999a). Globalization and Pay,” Proceedings of the American

Philosophical Society, Vol. 143, No. 2, June, 178-186.

Galbraith, James K. and Thomas Ferguson, (1999b).“The American Wage Structure, 1920-1947,” Research in Economic History, Vol. 19, 205-257.

Galbraith, James K. and Enrique Garcilazo, (2005). "Pay Inequality in Europe 1995-2000:

Convergence Between Countries and Stability Inside", European Journal of Comparative

Economics, December, Vol. 2, No. 2, 139-175.

Galbraith, James K. and Enrique Garcilazo, (2004). “Unemployment, Inequality and the Policy of Europe, 1984-2000,” Banca Nazionale del Lavoro Quarterly Review, Vol LVII, No. 228, March, 3-28.

Galbraith, James K. and Vidal Garza-Cantú, (1999). “Inequality in American Manufacturing Wages, 1920-1998: A Revised Estimate,” Journal of Economic Issues, Summer, 735-743. 
Galbraith, James K. and Travis Hale, (2008) State Income Inequality and Presidential Election Turnout and Outcomes, Social Science Quarterly, in press.

Galbraith, James K. and Travis Hale, (2006). “American Inequality: From IT Bust to Big Government Boom,” The Economists' Voice, vol. 3, issue 8, article 6.

Galbraith, James K., Ludmila Krytynskaia and Qifei Wang, (2004). "The Experience of Rising Inequality in Russia and China during the Transition." European Journal of Comparative Economics, Vol 1, No. 1.

Galbraith, James K. and Hyunsub Kum, (2005). “Estimating the Inequality of Household Incomes: Toward a Dense and Consistent Global Data Set,” Review of Income and Wealth, Series 51, Number 1, March, 115-143.

Galbraith, James K. and Hyunsub Kum, (2003). "Inequality and Economic Growth: A Global View Based on Measures of Pay" CESifo Economic Studies Vol. 49, 4, 527-556.

Galbraith, James K., Corwin Priest and George Purcell (2007), “Economic Equality and Victory in War: An Empirical Investigation,” Defense and Peace Economics.

Galbraith, James K., Deepshikha RoyChowdhury and Sanjeev Shrivastava, (2004). “Pay Inequality in the Indian Manufacturing Sector, 1979-1998, Economic and Political Weekly, New Delhi, Vol.39, No.28, July 10, 3139-3148. 
Galbraith, James K., Laura Spagnolo and Sergio Pinto, (2007). “Economic Inequality and Political Power: A Comparative Analysis of Argentina and Brazil," Business and Politics, Berkeley Electronic Press, 2007 (9) 1.

Galbraith, James K., Laura Spagnolo and Daniel Munevar (2008) “Inequidad salarial en Cuba durante el Período Especial”. América Latina Hoy 2008, vol. 48 (abril).

Garcilazo-Corredera J.E. (2007): Regional Labor Markets Unemployment and Inequality in Europe. Saarbrücken: VDM Verlag Dr. Müller e.K.

Giovannoni, Olivier (2007). "Inequality and the US Labor Force Structure," UTIP working paper 43, http://utip.gov.utexas.edu.

Harris, John R., and Michael P. Todaro, (1970). "Migration, Unemployment and Development: A Two-Sector Analysis." American Economic Review 60(1): 126-42.

Kim, Junmo (2002). The South Korean Economy: Toward A New Explanation of an Economic Miracle. London, Ashgate.

Kim, Junmo (2005). Globalization and Industrial Development, Lincoln: iUniverse. 
Kitov, Ivan O. (2005). "Modelling the average income dependence on work experience in the USA from 1967 to 2002," Working Paper 11, Society for the Study of Economic Inequality.

Kitov, Ivan O., (2007) "Modeling the evolution of Gini coefficient for personal incomes in the USA between 1947 and 2005," MPRA Paper 2798, University Library of Munich, Germany.

Kuznets, Simon, (1955), "Economic Growth and Income Inequality", American Economic Review 45, 1-28.

Li, Hongyi, Lyn Squire and Heng-fu Zou, (1998). "Explaining International and Intertemporal Variations in Income Inequality," Economic Journal, Royal Economic Society, vol. 108(446), January, 26-43.

Meidner, R., and G. Rehn, (1951). "Fackföreningrsrörelsen och den Fulla Sysselsättningen." LO. Stockholm.

Milanovic, B. (2002a), "The Ricardian Vice: Why Sala-i-Martin's calculation of world income inequality cannot be right", mimeo, September.

Milanovic, B. (2002b), "True world income distribution, 1988 and 1993: First calculation based on household surveys alone", Economic Journal, January 
Milanovic, B. (2007). Worlds Apart: Measuring International and Global Inequality, Princeton: Princeton University Press.

Perotti, R. (1996), "Growth, Income Distribution, and Democracy: What the Data Say", Journal of Economic Growth 1, 149-187.

Ram, Rati, (1997). "Level of Economic Development and Income Inequality: Evidence from the Postwar Developed World", Southern Economic Journal 64, 576-578.

Randolph, S. and W. Lott (1993), "Can the Kuznets Effect Be Relied on to Induce Equalizing Growth?", World Development 21, 829-840.

Meidner, R., and G. Rehn. 1951. "Fackföreningrsrörelsen och den Fulla Sysselsättningen." LO. Stockholm.

Robinson, S. (1976), "A Note on the U Hypothesis Relating Income Inequality and Economic Development", American Economic Review 66, 437-440.

Sala-i-Martin, X. (2002), The Disturbing “Rise” of Global Income Inequality. Xavier Sala-i-Martin. NBER Working Paper No. 8904. April.

Theil, H. (1972), Statistical Decomposition Analysis: with Application to the Social and 
Administrative Science, North Holland, Amsterdam and London.

University of Texas Inequality Project (http://utip.gov.utexas.edu)

\section{Notes}

1. Prepared for the Journal of Economic Inequality. I thank Ravi Kanbur for the invitation to submit this essay for consideration by the JOEI, and I thank the members of the UTIP team for comments on the draft.

2. This section is adapted from Galbraith and Kum (2003). Overall this discussion relates mainly to the OECD. However, the measurements described have implications for the global economy, which are summarized in Galbraith and Kum (2005) and Galbraith (2007c). Galbraith, Priest and Purcell (2007) develop an application to the outcomes of war.

3. Only a few studies using DS data address this problem. Deininger and Squire (1998) suggest adding 6.6 Gini points (on a scale of 100) to coefficients measured from expenditures to obtain a measure comparable to that obtained from income data. Li, Zou and Squire (1998) and Dollar and Kraay (2001) follow this suggestion. Barro (2000) uses dummy variables for different reference units in his estimations. However, no remedy has fully satisfied the critics.

4. Similarly, WIDER's Data Set Version 1.0 has 221 data points for 67 countries over 26 years from 1970 to 1996. According to Biancotti (2005), "These are the only data points out of 5067 that meet a standard of comparability.”

5. A further advantage of this data is that it can be displayed very attractively with Geographic Information Systems mapping.

6. The between groups component of Theil's $T$ is equal to the sum of the "Theil element" for each group, where the Theil element is the product of the group share in population, the ratio of group average income to total average income, and the log of that same ratio. Thus, for $\mathrm{m}$ groups:

$T^{B}=\sum_{i=1}^{m}\left\{\left(\frac{p_{i}}{P}\right) *\left(\frac{y_{i}}{\mu}\right) * \ln \left(\frac{y_{i}}{\mu}\right)\right\}$ where $\frac{p_{i}}{P}$ is a group population weight, and $\frac{y_{i}}{\mu}$ is the ratio of average income in group i to the average income of the whole population. Theil elements are positive for groups with above average income, negative for groups with below average income. The sum across groups is, however, always positive.

7. The within-groups component is, of course, simply unobserved. But the consistency implies that changes in the between-groups component track changes in the entire distribution, and this is the key point for time-series comparison. 
8. The observed population may not correspond exactly to the population that is of research interest; for example, because data may exclude employees of small establishments or those who work in the informal sector, and it may also exclude sources of income not derived from work. Significant distortions from these sources are possible. However, much experience suggests that what can be observed within the observed population is usually - not always -- a good proxy for what is happening in the whole population.

9. Similarly, disaggregation to the county level (in the U.S., 3150 counties), yields a precise picture whereas disaggregation to the state level (50 states plus the District of Columbia) yields a coarse image of the same picture.

10. In addition to OECD member countries (including Mexico and South Korea), UTIP papers are available on Russia, China, India, Argentina, Brazil, Costa Rica and Cuba. For example, Krytynskaia divided the Russian economy into some 1200 region-sector cells for each of eleven years, 1990 through 2000; Wang divided the Chinese economy into over 600 region-sector cells over the years 1979-1997. See references infra.

11. The figure displays the contribution of counties within New York state to overall U.S. inequality, measured across all counties. They are drawn from Local Area Personal Income Statistics, the computation was by Travis Hale. The New York counties are arranged in the legend and on the diagram from largest positive to largest negative contribution in the final year, which permits the relative contribution of each county and its evolution to be read at a glance. After Manhattan, Westchester and Nassau make the largest positive contributions. The Bronx and Kings make the largest negative contributions.

12. Where such time-series can be compared to high-quality, continuous sample surveys of income, as for the United States and Canada, the measures generally correspond well.

13. As in the case of UNIDO's Industrial Statistics or the European Commission's REGIO regional data set.

14. A further detail is that these measures can be obtained at very low cost. Source data are often available at no charge and the computation time is measured in hours.

15. Household income inequality gross of tax. Estimates on any other basis: net household income, gross or net expenditure, or personal as against household inequality, can be computed readily from the information generated by the EHII estimation procedure.

16. In the Americas, it is similarly clear that the concept of "national labor supply" has lost meaning to a degree: the United States has a large reserve in Mexico and points south, and an even larger virtual reserve in China, India, and elsewhere. However, the integration of capital and other markets between the U.S. and its trading partners is not nearly so complete as is the case in Europe.

17. Galbraith (2007b) argues that modern Europe resembles the United States of the 1930s, when a vast income differential dating to the Civil War separated the deep South from the rest of the country. This is comparable to the post Cold War differentials between Eastern and Western 
Europe. A relentless politics of regional income convergence, beginning with the New Deal, has largely erased the erstwhile regional differentials in the U.S.

18. The measure in Galbraith and Hale (2008) is the ratio of income inequality between census blocks, to the overall estimate of income inequality in the state.

19. The five counties are Santa Clara, San Francisco and San Mateo counties in California, King County, Washington (home to Microsoft), and New York, New York, the financial capital.

20. Property income in this context needs to be considered broadly, including salaries paid from funds raised on the capital markets, which became a significant source of personal incomes during the technology boom. 